\title{
Flores ornitófilas odoríferas: duas espécies de Palicourea (Rubiaceae) na Estação Biológica de Santa Lúcia, ES, Brasil
}

\author{
Cristiana Koschnitzke ${ }^{1,2}$, Ana Tereza de Araújo Rodarte ${ }^{1}$, Rita de Cássia Ribeiro Gama ${ }^{1}$ e \\ Frederico Tapajós de Souza Tâmega ${ }^{1}$
}

Recebido: 29.01.2009; aceito: 10.06.2009

ABSTRACT - (Scented ornithophilous flowers: two species of Palicourea (Rubiaceae) in the Estação Biológica de Santa Lúcia, ES, Brazil). Palicourea guianensis and P. marcgravii have inflorescences and flowers with bright coloration. Their flowers are tubular hummingbird pollinated but they are visited by butterflies too. These flowers have sweet odour and their corolla tube colored when treated with neutral red. It's possible to be a case of mixed pollination syndrome or represent vestiges of a scented ancestry in phylogenetic lineage.

Key words: Floral odour, ornithophily, Palicourea, Rubiaceae

RESUMO - (Flores ornitófilas odoríferas: duas espécies de Palicourea (Rubiaceae) na Estação Biológica de Santa Lúcia, ES, Brasil). Palicourea guianensis e P. marcgravii possuem inflorescências e flores de colorido vivo. Suas flores são tubulares e polinizadas por beija-flores, mas elas são visitadas também por borboletas. Estas flores apresentam odor suave e com o método do vermelho neutro o tubo da corola ficou corado. É possível que seja um caso de síndrome de polinização mista ou a emissão de odor seria uma característica ancestral dentro de uma linhagem filogenética.

Palavras-chave: Ornitofilia, Palicourea, perfume floral, Rubiaceae

\section{Introdução}

Palicourea Aublet possui cerca de 200 espécies distribuídas pelas florestas neotropicais; suas flores apresentam corola tubular vividamente colorida e são polinizadas por beija-flores (Taylor 1997). Várias espécies de Palicourea já tiveram sua biologia reprodutiva estudada (Sobrevilla et al. 1983, Feinsinger \& Busby 1987, Ree 1997, Coelho \& Barbosa 2003, Lau \& Bosque 2003, Mendonça \& Anjos 2006) devido à heterostilia que ocorre com freqüência não somente nas espécies desse gênero, mas também em outros da família Rubiaceae. A maioria desses trabalhos registra a ausência de odor nas flores de Palicourea, com exceção de P.petiolaris Kunth (Sobrevilla et al. 1983) em que é descrito odor adocicado em suas flores de corola brancoamarelada; P. andrei cujas flores apresentam corola tubular branca e são adocicadamente perfumadas e P. candida C.M. Taylor também com flores brancas, perfumadas, com tubo relativamente longo e possivelmente adaptadas a polinização noturna por esfingídeos (Taylor 1997).
O objetivo desta nota científica é divulgar que espécies de Palicourea, que apresentam flores com características ornitófilas, podem apresentar odor.

\section{Material e métodos}

Durante aulas práticas do curso de Ecologia da Polinização do Programa de Ciências Biológicas (Botânica) do Museu Nacional (UFRJ), realizadas de 06 a 09 de dezembro de 2005 às margens do Rio Timbuí, na Estação Biológica Santa Lúcia, Santa Teresa, ES, foram feitas cerca de $18 \mathrm{~h}$ de observações de campo de indivíduos de Palicourea guianensis Aubl. e P. marcgravii A. St. Hil.. Estas espécies são arvoretas de aproximadamente três metros de altura que ocorrem próximas na área de estudo, em subbosque da Mata Atlântica. Os visitantes florais destas espécies foram observados quanto à sua assiduidade às flores. Fotografias foram tiradas para identificação dos visitantes florais. As flores foram colocadas em solução aquosa de vermelho neutro segundo técnica de Vogel (1983). Flores também foram acondicionadas em vidros com tampas para concentração de odores

1. Universidade Federal do Rio de Janeiro, Museu Nacional, Departamento de Botânica, Quinta da Boa Vista, $20940-040$ São Cristóvão, Rio de Janeiro, RJ, Brasil.

2. Autor para correspondência: cristianaufrjmnlbra@ig.com.br 
que posteriormente foram abertos para constatação da presença de odor. A concentração de açúcares no néctar foi medida com refratômetro de bolso. Os beija-flores foram identificados por comparação de fotos, através de bibliografia (Ruschi 1982) e com espécimes em exposição no Museu Mello Leitão. A borboleta foi identificada por comparação com Brown \& Freitas (2000).

\section{Resultados}

Palicourea guianensis e P.marcgravii apresentam inflorescências bem expostas para fora da folhagem apresentando forte colorido; suas flores são heterostílicas e possuem suave odor adocicado.

As inflorescências de Palicourea guianensis são piramidais voltadas para cima, com comprimento médio de $21,7 \mathrm{~cm}(16-25 \mathrm{~cm}, \mathrm{n}=10)$, possuem raque e pedicelos vermelho-alaranjados. O número médio de flores por inflorescência é de 337,6 (129 - 617,n = 10). A média de flores em antese por inflorescência é de 5,5. A corola é totalmente amarela, medindo em média 9,6 mm de comprimento por $2,55 \mathrm{~mm}$ de diâmetro na fauce. As flores ficam posicionadas lateralmente, mas voltadas para cima. A concentração de açúcares do néctar foi de $16 \%-17 \%$. No teste com vermelho neutro coraram-se as faces abaxial e adaxial das lacínias.

Palicourea marcgravii possui inflorescências do tipo dicásio voltadas, em geral, para as laterais da folhagem; apresentam comprimento médio de 7,2 $\mathrm{cm}(5-9 \mathrm{~cm}, \mathrm{n}=8)$ e possuem raque e pedicelos vermelho-alaranjados. O número médio de flores por inflorescência é de $35(13-66, n=10)$. A média de flores em antese por inflorescência é de 1,5. A corola é amarela na porção basal do tubo e gradativamente, em direção ao ápice das lacínias, torna-se branca com pequenas saliências de cor arroxeada na superfície externa da corola conferindo uma aparente coloração lilás. O tubo da corola mede em média $22,7 \mathrm{~mm}$ de comprimento e o diâmetro da fauce, 5,1 mm. As flores ficam posicionadas lateralmente. A concentração de açúcares no néctar variou de $22 \%$ - 26\%. No teste com vermelho neutro corou-se o último terço apical da corola por dentro e por fora.

Os visitantes florais observados e identificados foram os beija-flores Ramphodon naevius (Dumont, 1818) e Aphantochroa cirrochloris (Vieillot 1818) e a borboleta Nymphalidae - Ithomiinae, Melinaea ludovica paraiya (Reakirt 1866).

Ramphodon naevius foi o único beija-flor observado visitando as flores de Palicourea marcgravii, e não foi observado visitando flores de $P$. guianensis apesar da localização próxima das plantas.

Pelo menos quatro espécies de beija-flores visitaram as flores dos indivíduos de Palicourea guianensis observados neste trabalho, sendo possível somente identificar Aphantochroa cirrochloris que realizou o maior número de visitas.

A borboleta Melinaea ludovica paraiya visitou as flores das duas espécies de Palicourea sendo mais frequente em $P$. marcgravii.

\section{Discussão}

Já está comprovado que os beija-flores visitam vários tipos de flores que não apresentam características ornitófilas (Buchmann \& Nabhan 1996), contudo, poucos são os registros de flores com características ornitófilas que apresentem odor. Dentre eles está o de Knudsen et al. (2004) que levantaram a composição química do odor floral de plantas polinizadas por beijaflores no Equador, detectando a presença de odor em oito das 17 espécies estudadas, mas nenhuma delas pertencente à família Rubiaceae.

Palicourea guianensis e P. marcgravii enquadramse na síndrome de ornitofilia (Endress 1996) exceto pelo fato da presença de odor floral. Além das visitas dos beija-flores, estas duas espécies também são visitadas e possivelmente polinizadas por borboletas o que poderia ser interpretado como uma síndrome de polinização mista. Knudsen et al. (2004) também admitem que os táxons por eles estudados podem ter síndromes de polinização mistas, sendo que o odor produzido serviria para atrair polinizadores alternativos.

As espécies de Palicourea citadas até o momento como odoríferas diferem das aqui estudadas por apresentarem flores brancas ou branco-amareladas, mais associadas à polinização por insetos (Sobrevilla et al. 1983, Taylor 1997). O gênero Palicourea está intimamanete relacionado ao gênero Psychotria, principalmente ao subgênero Heteropsychotria, que apresenta a maioria das espécies polinizada por pequenos insetos (Taylor 1997, Sakai \& Wright 2008). Knudsen et al. (2004) cogitam que o odor nas flores ornitófilas possivelmente seja uma característica ancestral dentro de uma linhagem monofilética de plantas.

Seria interessante verificar se as espécies de Palicourea já estudadas realmente não apresentam odor, já que por uma convenção de que flores ornitófilas não possuem perfume, os pesquisadores das 
espécies em questão podem não têm se preocupado em investigar melhor essa característica floral em seus estudos.

\section{Agradecimentos}

Ao Museu Mello Leitão que cedeu o alojamento da Estação Biológica de Santa Lúcia. Ao biólogo do Museu Nacional,Eduardo Martins Barros, pelo apoio técnico no campo. À CAPES pelo financiamento das aulas práticas da disciplina Ecologia da Polinização, fornecido através do Programa de Pós-Graduação em Ciências Biológicas (Botânica), Museu Nacional, UFRJ.

\section{Literatura citada}

Brown Jr., K.S. \& Freitas, A.V.L. 2000. Diversidade de Lepidoptera em Santa Teresa, Espírito Santo. Boletim do Museu de Biologia Mello Leitão, nova série 11/12: 71-118.

Buchmann, S.L. \& Nabhan, G.P. 1996. The forgotten pollinators. Island Press, Washington, DC.

Coelho, C.P. \& Barbosa, A.A.A. 2003. Biologia reprodutiva de Palicourea macrobotrys Ruiz \& Pavon (Rubiaceae): um possível caso de homostillia no gênero Palicourea Aubl. Revista Brasileira de Botânica 26: 403-413.

Endress, P.K. 1996. Diversity and evolutionary biology of tropical flowers. Cambridge University Press, Cambrigde.

Feinsinger, P. \& Bosby, W.H. 1987. Pollen carryover: experimental comparisons between morphs of Palicourea lasiorrachis (Rubiaceae), a distylous, birdpollinated, tropical treelet. Oecologia 73: 231-235.

Knudsen, J.T., Tollsten, L., Groth, I.B. \& Raguso, R.A. 2004. Trends in floral scent chemistry in pollination syndromes: floral scent composition in hummingbirdpollinated taxa. Botanical Journal of the Linnean Society 146: 191-199.

Lau, P. \& Bosque, C. 2003. Pollen flow in the distylous Palicourea fendleri (Rubiaceae): an experimental test of the disassortative pollen flow hypothesis. Oecologia 135: 593-600.

Mendonça, L.B. \& Anjos, L. 2006. Flower morphology, nectar features, and hummingbird visitation to Palicourea crocea (Rubiaceae) in the upper Paraná River floodplain, Brazil. Anais da Academia Brasileira de Ciências 78: 45-57.

Ree, R.H. 1997. Pollen flow, fecundity, and the adaptive significance of heterostyly in Palicourea padifolia (Rubiaceae). Biotropica 29: 298-308.

Ruschi, A. 1982. Beija-flores do estado do Espírito Santo. Editora Rios, São Paulo.

Sakai, S. \& Wright, S.J. 2008. Reproductive ecology of 21 coexisting Psychotria species (Rubiaceae): when is heterostyly lost? Biological Journal of the Linnean Society 93: 125-134.

Sobrevilla, C., Ramirez, N. \& Enrech, N.X. 1983. Reproductive biology of Palicourea fendleri and $P$. petiolaris (Rubiaceae), heterostylous shrubs of a Tropical Cloud Forest in Venezuela. Biotropica 15: 161-169.

Taylor, C.M. 1997. Conspectus of the genus Palicourea (Rubiaceae: Psychotrieae) with the description of some new species from Ecuador and Colombia. Annals of the Missouri Botanical Garden 84: 224-262.

Vogel, S. 1983. Ecophysiology of zoophilic pollination. In: O.L. Lange, P.S. Nobel, C.B. Osmond \& H. Ziegler (eds.). Physiological plant ecology III. Encyclopedia of Plant Physiology. New Series, 12C. Springer-Verlag, Berlin, pp. 559-624. 
